\title{
Origin of Enantioselectivity Reversal in Lewis Acid-Catalyzed Michael Additions Relying on the Same Chiral Source
}

\author{
Paul S. Riehl ${ }^{\dagger}$, Alistair D. Richardson†, Tatsuhiro Sakamoto ${ }^{\dagger}$ Jolene P. Reid*§ and Corinna S. Schindler*†. \\ †Willard Henry Dow Laboratory, Department of Chemistry, University of Michigan, 930 North University Avenue, Ann \\ Arbor, Michigan 48109, United States \\ §University of Utah, Department of Chemistry, 315 South 1400 East, Salt Lake City, Utah 84112, United States \\ KEYWORDS Dual enantioselective control, reversal of enantioselectivity, enantiodivergence, chirality inversion, Lewis \\ acid catalysis, enantioselective Michael additions.
}

\begin{abstract}
Enantiodivergence is an important concept in asymmetric catalysis that enables access to both enantiomers of a product relying on the same chiral source. This strategy is particularly appealing as an alternate approach when only one enantiomer of the required chiral ligand is readily accessible but both enantiomers of the product are desired. Despite their potential significance, general catalytic methods to induce reversal in enantioselectivity remain underdeveloped. Herein we report our studies focused on elucidating the origin of enantioselectivity reversal in Lewis acid-catalyzed Michael additions relying on the same enantiomer of ligand as the chiral source. Our results provide a detailed mechanistic understanding of this transformation based on experimental and computational investigations which reveal the important interplay between kinetics and thermodynamics responsible for the observed enantiodivergence.
\end{abstract}

\section{Introduction}

Asymmetric synthesis enables access to chiral complex molecules which is particularly desirable as distinct enantiomers can exhibit different biological activity. In asymmetric catalysis, ${ }^{1}$ chiral induction is often conferred by optically active molecules of natural origin that function as ligands ${ }^{2}$ in metal complexes (Figure 1A). Consequently, the synthesis of both enantiomers of a target structure generally requires access to both enantiomers of a chiral catalyst. However, many naturally occurring chiral pool reagents ${ }^{3}$ used to synthesize chiral ligands are often available in only one absolute configuration. ${ }^{4}$ Enantiodivergent catalytic strategies ${ }^{5}$ can represent intriguing alternatives to overcome this limitation by transferring chirality of a single chiral source to selectively obtain either enantiomer of a product (Figure 1B). Several reports observing a reversal in enantioselectivity with the same chiral source exist, including the use of distinct metals, ${ }^{6}$ counterions, ${ }^{7}$ the introduction of subtle structural modifications of the catalyst system, ${ }^{8}$ or simply changes in solvent or temperature. ${ }^{9}$ Nevertheless, the design of effective and general catalytic asymmetric methods to induce complete reversals in enantioselectivity continues to be a challenge. ${ }^{5, \mathrm{f}}$ Importantly, often only one of the two enantiomers is obtained in high enantiomeric excess since it is difficult to induce large energy differences between transition states that lead to the competing products required for effective enantiodivergence. Thus, it is imperative to identify the origin of such enantioselectivity reversal and yet, these transformations remain poorly understood. ${ }^{5,6}$ The ability to design or anticipate strategies that would afford effective enantiodivergence is highly valuable to
Figure 1: Select strategies in asymmetric catalysis to access both enantiomers of product.

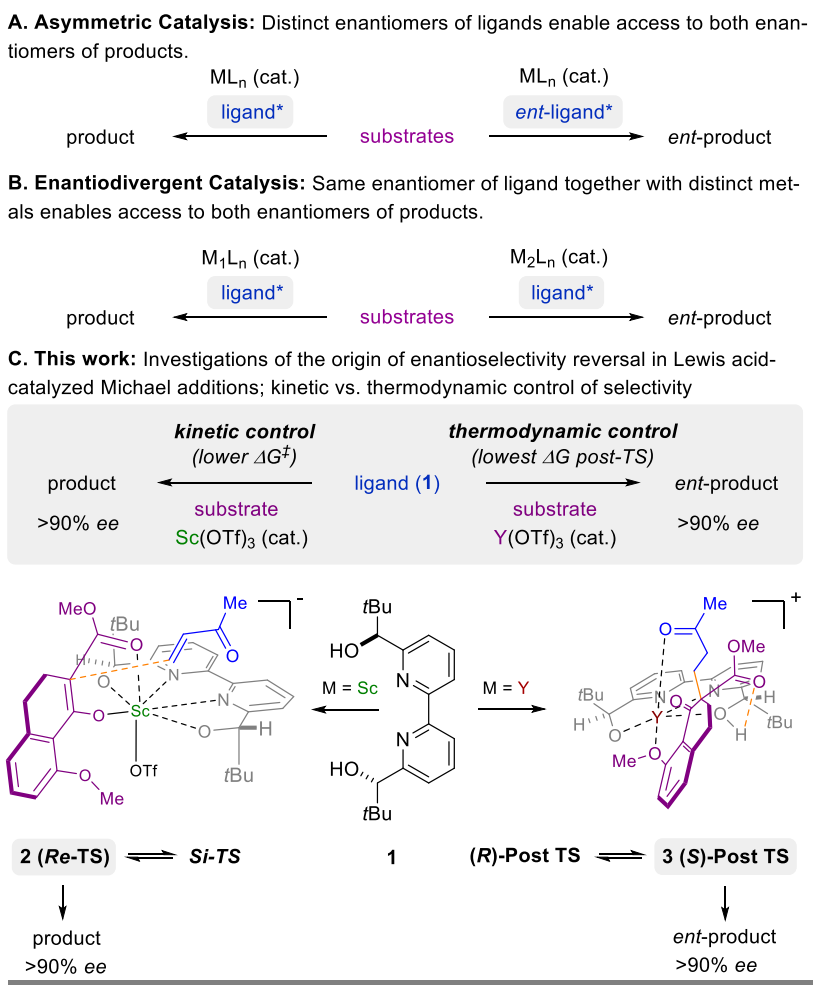

synthetic chemists. One promising approach could center on well-defined chiral ligands whose complexes with distinct metals may enable sufficient geometric and energetic differences between the relevant transition states. Consequently, this should allow high levels of enantiodivergence 
Table 1. Optimization of the enantioselective Michael addition.

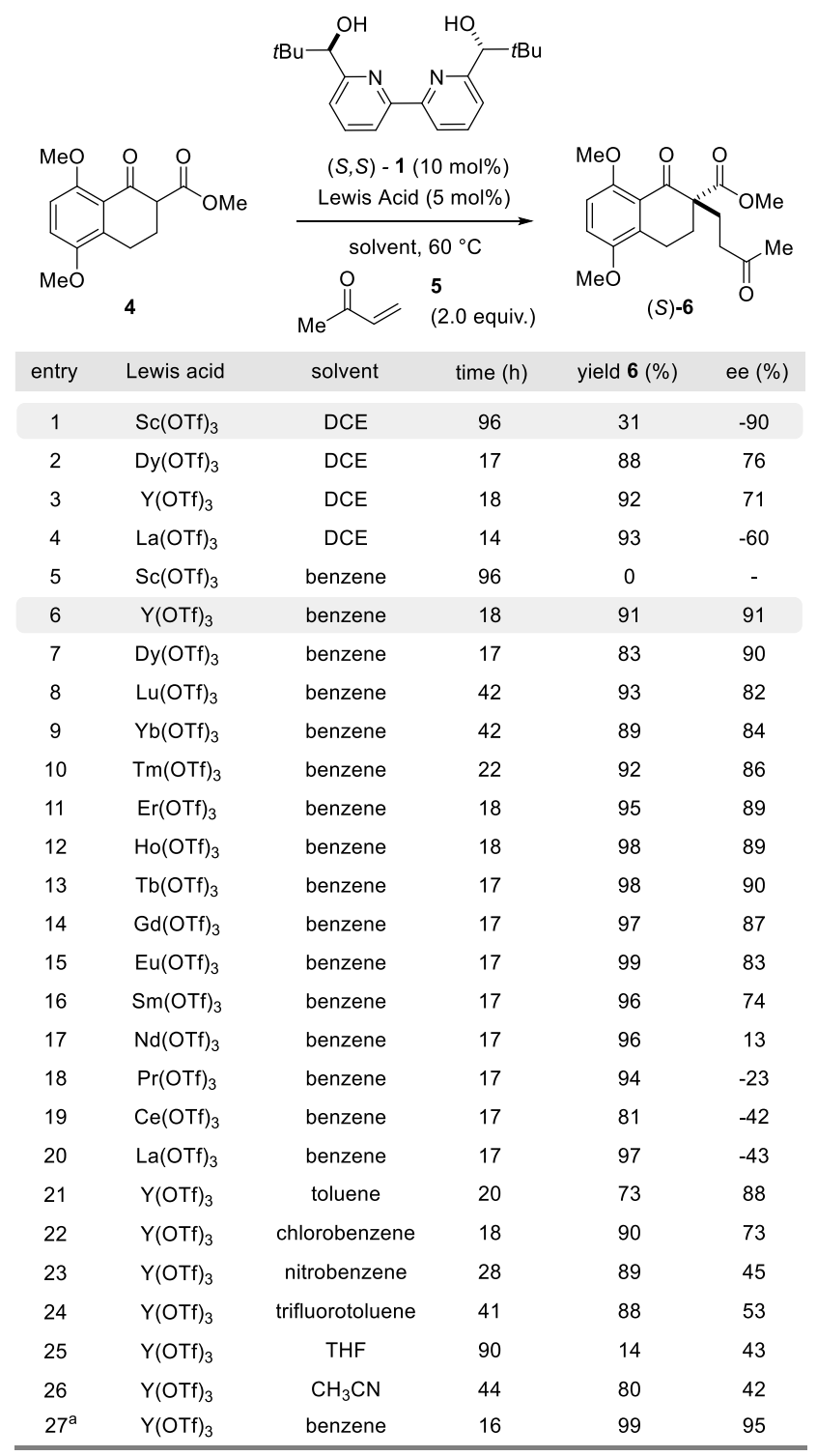

Conditions: $10 \mathrm{~mol} \% 1$ and $5 \mathrm{~mol} \% \mathrm{M}(\mathrm{OTf})_{3}$ were pre-stirred at $60{ }^{\circ} \mathrm{C}(1 \mathrm{hr})$. Reactions were performed on $0.15 \mathrm{mmol}$ scale in the listed solvent $(0.02 \mathrm{M})$ at $60^{\circ} \mathrm{C}$ for the listed time. a) reaction performed at $80^{\circ} \mathrm{C}$ and $0.04 \mathrm{M}$

to be achieved. ${ }^{4}$ This approach is based on the intrinsic characteristics of the central metals such as ionic radius and electron configuration that lead to the formation of structurally and electronically distinct complexes upon binding to the same chiral ligand. If the chiral ligand is well-defined,enantiodivergence can result, for example, through different coordinations of the ligand or the substrate to the metal center and induce profound variations in the catalyst's chiral environment. We recently deployed such a strategy to complete the enantiodivergent total synthesis of $(+)$ and $(-)$-lingzhiol. ${ }^{10}$ Harnessing different catalyst designs by changing the central metal is therefore possible, but the mechanistic underpinnings have remained underexplored. In this context, we herein report our studies, which integrate experimental and computational tools to understand the origin of enantiodivergence in Lewis acid catalyzed ${ }^{11-14}$ Michael additions relying on bipyridine ligand (1) and refine our initial hypothesis of substrate-controlled reversal of enantioselectivity (Figure 1C). ${ }^{15}$
In these investigations, both the identity of the Lewis acid complex and the substrate were systematically modified to probe the importance of such components in achieving high levels of selectivity for either enantiomer. Focusing on the two most selective Lewis acids, we determined through density functional theory (DFT) calculations that for scandium-based complexes, the product distribution is controlled by the kinetics of carbon-carbon bond formation. Conversely, for yttrium, enantioselectivity arises from the thermodynamically preferred Lewis acid-product complex. In addition to the central metal, ${ }^{16}$ the substrate was found to play a key role in achieving high enantiodivergence. Importantly, the substrate structure affects the stability of the post-transition state complexes following Michael addition, directly impacting the selectivity arising from a thermodynamic controlled reaction pathway. Given the prominence of Lewis acids in asymmetric catalysis, we expect that the insights described in this report will further advance our understanding of Lewis acid-catalyzed reversal of enantioselectivity and enable the design and development of general strategies to achieve high enantiodivergence.

\section{Results and Discussion}

During our efforts towards the enantioselective total synthesis of lingzhiol, ${ }^{10}$ we investigated the conjugate addition between $\beta$-ketoester $\mathbf{4}$ and methyl vinyl ketone $\mathbf{5}$ catalyzed by $\mathrm{Sc}(\mathrm{OTf})_{3}$ and bipyridine ligand $\mathbf{1}$ under conditions developed by Kobayashi and coworkers. ${ }^{17}$ Although the reaction proceeded with a high enantioselectivity of $90 \%$ ee, the desired product was only isolated in $31 \%$ yield (entry 1, Table 1). In an effort to improve the conversion of this transformation, we evaluated a variety of metal triflates to identify higher-yielding conditions for the formation of Michael adduct 6. ${ }^{16}$ Higher yields and conversions were observed with $\operatorname{Dy}(\mathrm{OTf})_{3}, \mathrm{Y}(\mathrm{OTf})_{3}$, and La(OTf $)_{3}$ in $88 \%$ ee, $92 \%$ ee, and $93 \%$ ee, respectively in shorter overall reaction times while moderate to good enantioselectivities of up to $76 \%$ ee were obtained (entries 2-4, Table 1). Interestingly, catalytic

Table 2: Selected metal triflates, their ionic radii, and performance in the enantioselective Michael reaction.

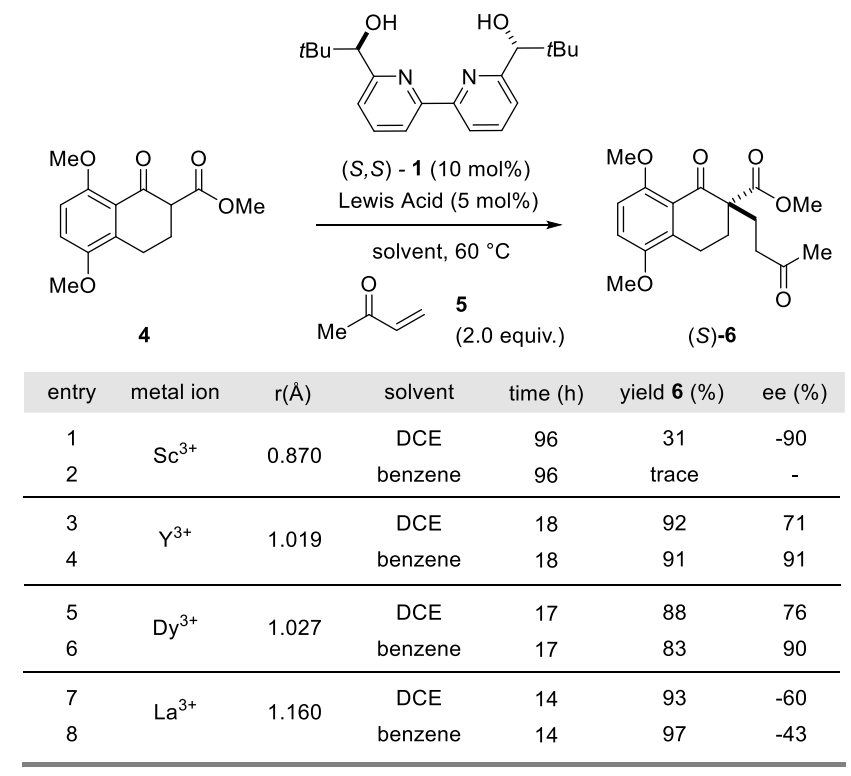

Conditions: $10 \mathrm{~mol} \% 1$ and $5 \mathrm{~mol} \% \mathrm{M}(\mathrm{OTf})_{3}$ were pre-stirred at $60{ }^{\circ} \mathrm{C}(1 \mathrm{hr})$ Reactions were performed on $0.15 \mathrm{mmol}$ scale in the listed solvent $(0.02 \mathrm{M})$ at $60{ }^{\circ} \mathrm{C}$ for the listed time. 
amounts of Dy(OTf $)_{3}$ and Y(OTf $)_{3}$ favored the opposite enantiomer of the product when compared to Sc(OTf) $)_{3}$ despite employing the same enantiomer of ligand $1(S, S-\mathbf{1})$. Importantly, Kobayashi and coworkers were previously able to show that this ligand system can induce metal-dependent enantiodivergence in the opening of meso-epoxides albeit relying on scandium and copper as metals. ${ }^{6 \mathrm{~d}}$ In subsequent efforts, we focused on the evaluation of additional solvents and observed improved enantioselectivities for $\mathrm{Y}(\mathrm{OTf})_{3}$ and Dy(OTf $)_{3}$ with $91 \%$ ee and $90 \%$ ee, respectively when switching to benzene while high yields were maintained (entries 6 and 7, Table 1). In comparison, catalytic amounts of Sc(OTf $)_{3}$ in benzene under otherwise identical conditions did not result in the formation of Michael adduct 6 even after extended reaction times (entry 5, Table 1). Ensuing efforts centered on the investigation of commercially available lanthanide(III) triflate salts with benzene as reaction solvent. Specifically, catalytic amounts of $\mathrm{Lu}(\mathrm{OTf})_{3}$ and $\mathrm{Yb}(\mathrm{OTf})_{3}$ led to complete conversion of $\beta$-ketoester $\mathbf{4}$ after 42 hours and results in $93 \%$ and $89 \%$ yield of product 6 in $82 \%$ ee and $84 \%$ ee, respectively (entries 8 and 9 , Table 1 ). Additionally, $\operatorname{Tm}(\mathrm{OTf})_{3}, \quad \operatorname{Er}(\mathrm{OTf})_{3}, \quad \mathrm{Ho}(\mathrm{OTf})_{3}, \operatorname{Tb}(\mathrm{OTf})_{3}$, $\mathrm{Gd}(\mathrm{OTf})_{3}$, and $\mathrm{Eu}(\mathrm{OTf})_{3}$ all afforded high yields of up to $99 \%$ while the same enantiomer of product $\mathbf{6}$ was formed with high enantioselectivities of up to $90 \%$ ee (entries 10-15, Table 1). Catalytic amounts of $\mathrm{Sm}(\mathrm{OTf})_{3}$ similarly afforded

Figure 2: Plot of $\log ($ e.r.) vs. ionic radii of distinct lanthanides.

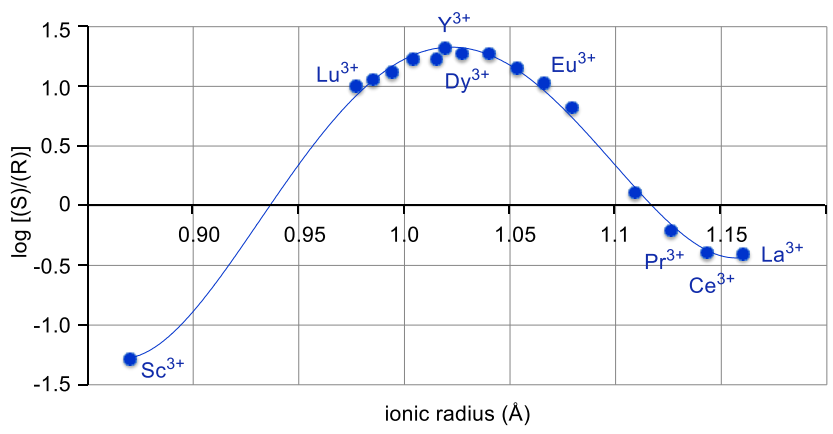

high yields of product 6 in $96 \%$ albeit with only moderate enantiomeric excess of 74\% (entry 16, Table 1). Furthermore, $\mathrm{Nd}(\mathrm{OTf})_{3}$ provided product 6 in $96 \%$ yield although in only $13 \%$ ee (entry 17 , Table 1 ). In comparison, catalytic amounts of $\operatorname{Pr}(\mathrm{OTf})_{3}, \mathrm{Ce}(\mathrm{OTf})_{3}$ and $\mathrm{La}(\mathrm{OTf})_{3}$ afforded the desired product 6 in up to $97 \%$ yield but with only moderate ee (entries 18-20, Table 1). Interestingly, relying on these lanthanides the opposite enantiomer of 6 was again favored, similar to the results observed relying on $\mathrm{Sc}(\mathrm{OTf})_{3}$ as Lewis acid catalyst. Additional solvents were evaluated together with $\mathrm{Y}(\mathrm{OTf})_{3}$ as catalyst, however only toluene was comparable to benzene resulting in product $\mathbf{6}$ in $73 \%$ yield and $88 \%$ ee (entries 21-26, Table 1).

Metal ionic radii: Metal-dependent reversal of enantioselectivity has been previously attributed to the distinct ionic radii of the central metal. ${ }^{5}$ Table 2 correlates the optimal reaction conditions identified for the selective formation of either enantiomer of $\mathbf{6}$ together with the respective ionic radius of the lanthanide. While dichloroethane proved superior as solvent with the smaller scandium as metal center, no formation of the desired product was observed in benzene, presumably due to low solubility of the Lewis acid catalyst (entries 1-2, Table 2). ${ }^{18}$ In comparison, the larger yt- trium-based catalyst displayed superior reactivity in benzene (entries 3-4, Table 2). Moreover, when the log of the enantiomeric ratio of product $\mathbf{6}$ is plotted against the ionic radius of the metal catalyst, a bell-shaped curve is observed

Figure 3: Nonlinear effect studies of the scandium- and yttrium-catalyzed enantiodivergent Michael addition.
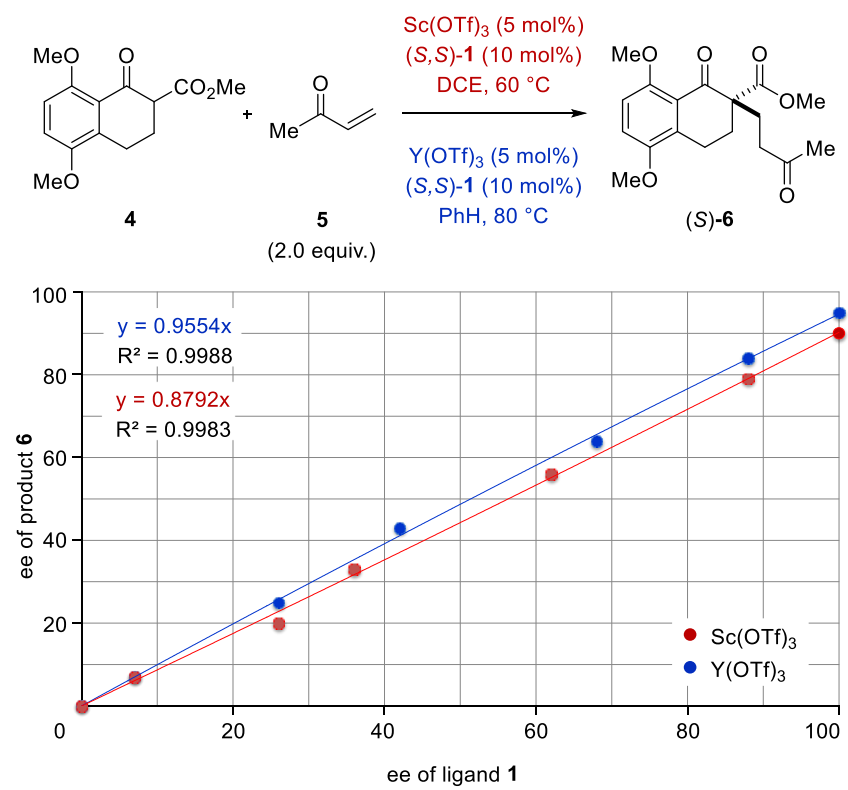

(Figure 2). This is consistent with previous literature reports correlating ionic radii to enantiomeric excess. ${ }^{6 a-c}$ Interestingly, the formation of one enantiomer is strongly favored with the small scandium metal while increasing the ionic radius to $1.019 \AA$ in yttrium leads to the selective formation of the opposite enantiomer. However, a further increase in metal ionic radii reverses this trend to favor the formation of the inital enantiomer albeit with lower enantioselectivities. These results suggest that structurally distinct metal complexes form upon binding of ligand 1 to metals varying in their metal ionic radii leading to the observed reversal of facial selectivity.

Nonlinear effect studies: The origin of enantiodivergence in metal-controlled reversals of enantioselectivity is often attributed to these different coordination modes characteristic for larger compared to smaller metals. However, a reversal of enantioselectivity has also been observed due to the formation of metal-ligand aggregates or metal complexes varying in their metal to ligand ratio. ${ }^{19}$ To gain additional

Figure 4: Potential metal-ligand binding modes between Sc/Y and ligand $\mathbf{1}$.
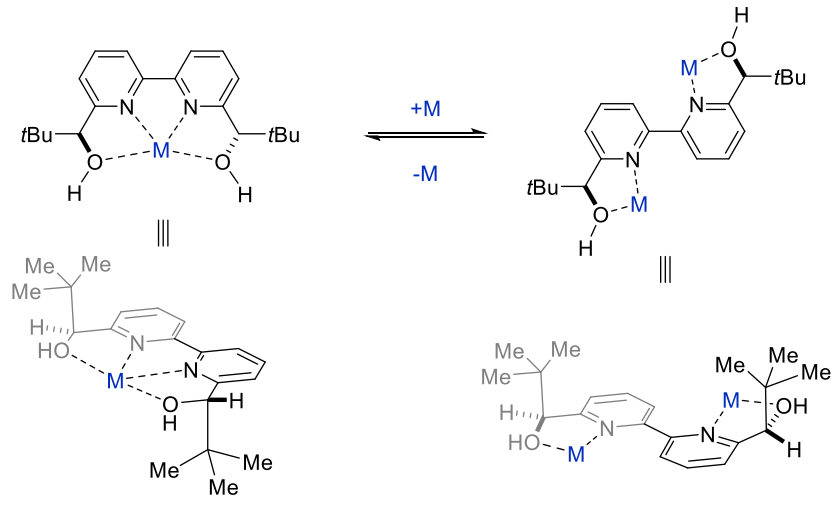
Figure 5: Kinetic investigations of the scandium- and yttriumcatalyzed enantiodivergent Michael addition.

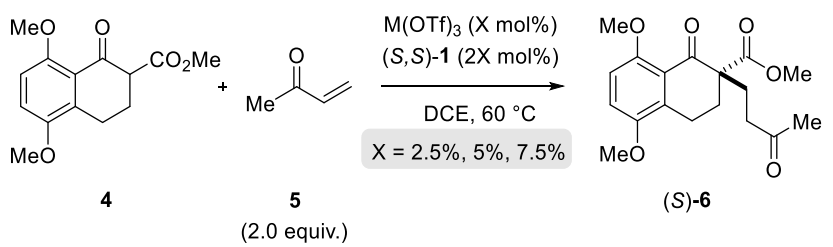

order in Sc(OTf) $)_{3}: \quad 0.91 \pm 0.07$

order in $\mathrm{Y}(\mathrm{OTf})_{3}: \quad 1.02 \pm 0.07$

Conditions: $2 \mathrm{X} \mathrm{mol} \% 1$ and $\mathrm{X} \mathrm{mol} \% \mathrm{M}(\mathrm{OTf})_{3}$ were pre-stirred at $60{ }^{\circ} \mathrm{C}(30 \mathrm{~min})$. Reactions were performed on $0.057 \mathrm{mmol}$ scale in the listed solvent $(0.018 \mathrm{M})$ at 60 ${ }^{\circ} \mathrm{C}$ with monitoring at regular intervals. Reactions were performed in triplicate.

insights into the controlling features of this enantiodivergent Michael addition, we conducted nonlinear effect studies ${ }^{20}$ with scandium- and yttrium-based Lewis acids (Figure 3). Importantly, both scandium- and yttrium-catalyzed reactions show a linear relationship between enantiomeric excess of ligand and enantiomeric excess of the Michael adduct 6 (Figure 3). This result is consistent with one equivalent of the chiral ligand $\mathbf{1}$ being incorporated in the catalytically active species in both the scandium- and yttrium-catalyzed reaction pathways.

Kinetic studies: To determine whether more than one equivalent of the Lewis acidic metal is involved in the active catalyst, we conducted kinetic investigations of both the scandium- and yttrium-catalyzed transformations. Importantly, in studies focused on aqueous Mukaiyama aldol reactions relying on bipyridine 1 as chiral ligand and $\mathrm{Bi}(\mathrm{OTf})_{3}$ as

Table 3: Evaluation of structural requirements of pyridyl ligands.

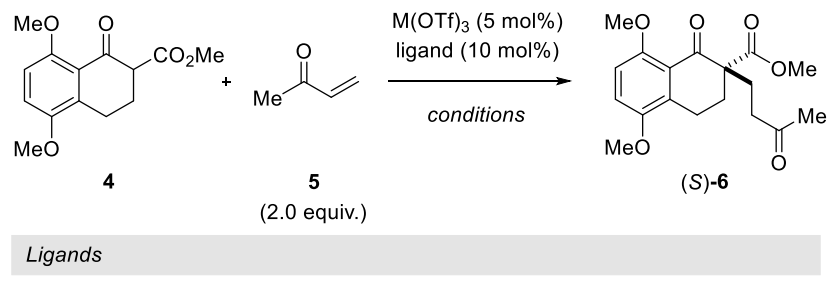

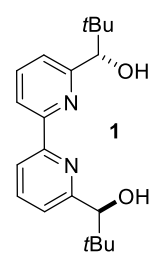

Sc: $\quad 31 \% ;-90 \%$ ee

Y: $\quad 99 \% ; 93 \%$ ee

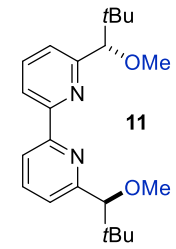

Sc: $81 \% ; 0 \%$ ee

Y: $\quad 79 \% ; 0 \%$ ee

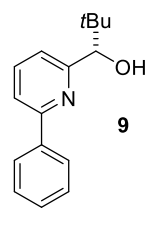

Sc: $78 \% ; 0 \%$ ee

Y: $\quad 93 \% ; 0 \%$ ee

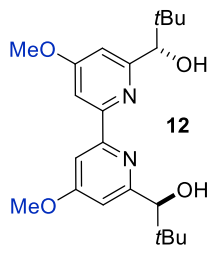

Sc: $59 \% ;-91 \%$ ee

Y: $\quad 97 \% ; 91 \%$ ee

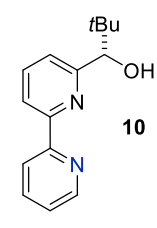

Sc: $79 \% ; 0 \%$ ee

Y: $71 \% ; 0 \%$ ee

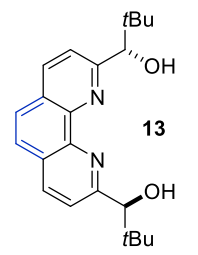

Sc: $\quad 35 \% ;-85 \%$ ee Y: $\quad 55 \% ; 90 \%$ ee
Conditions: $10 \mathrm{~mol} \%$ of the ligand and $5 \mathrm{~mol} \% \mathrm{M}(\mathrm{OTf})_{3}$ were pre-stirred at $60{ }^{\circ} \mathrm{C}(30$ $\mathrm{min})$. Reactions were performed on 0.15 or $0.076 \mathrm{mmol}$ scale in DCE $\left(\mathrm{Sc}(\mathrm{OTf})_{3}\right)$ at $60{ }^{\circ} \mathrm{C}(0.02 \mathrm{M})$ or benzene $\left(\mathrm{Y}(\mathrm{OTf})_{3}\right)$ at $80{ }^{\circ} \mathrm{C}(0.04 \mathrm{M})$.
Lewis acid, Kobayashi and coworkers observed that excess ligand was required to maintain high enantioselectivity of the product formed. ${ }^{21}$ Specifically, a 1:1 metal/ligand complex (7) was favored when excess ligand was present while excess metal promoted a competing bimetallic binding mode 8 (Figure 4). Initial ${ }^{1} \mathrm{H}$-NMR studies following the chemical shift of the characteristic methine proton of the ligand are consistent with a tetradentate binding mode 7 of the bipyridine 1 to both scandium and yttrium (see Supporting Information for details). To gain additional support for this hypothesis, we conducted subsequent kinetic investigations of the enantiodivergent Michael addition. Specifically, we opted to study the initial rates of both reactions in dichloroethane at $60{ }^{\circ} \mathrm{C}$ as both Lewis acids, Y(OTf $)_{3}$ and $\mathrm{Sc}(\mathrm{OTf})_{3}$ form effective catalysts with the bipyridine ligand 1 under these reaction conditions resulting in high yields and moderate to excellent enantiomeric excess while the observed reversal of enantioselectivity is maintained (entries 1-4, Table 2). In our studies, 2.5\%, 5\%, and 7.5\% loadings of each metal catalyst were investigated and the superior 2:1 ligand to metal ratio previously identified during our reaction optimization was maintained. For the comparatively fast Y(OTf) $)_{3}$-catalyzed transformation, the yield of product

Table 4: Evaluation of differentially $\mathrm{MeO}$-substituted aryl $\beta$ keto-ester substrates
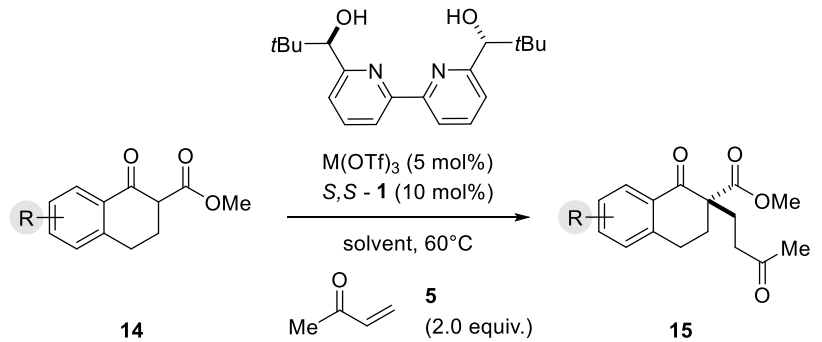

Substrate structure

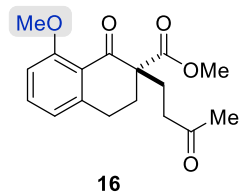

Sc: $15 \% ;-85 \%$ ee Y: $94 \% ; 90 \%$ ee

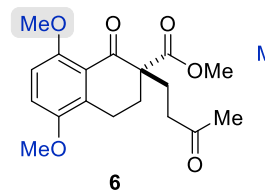

Sc: $31 \% ;-90 \%$ ee Y: $\quad 99 \% ; 95 \%$ ee

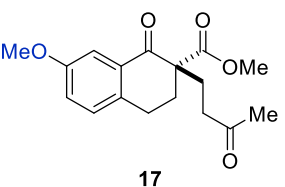

Sc: $46 \% ;-90 \%$ ee Y: $94 \% ; 17 \%$ ee<smiles></smiles>

Sc: $29 \%$; $-90 \%$ ee $\quad$ Sc: $89 \%$; $-97 \%$ ee $\quad$ Sc: $93 \% ;-93 \%$ ee Y: $\quad 92 \% ; 7 \%$ ee $\quad$ Y: $\quad 94 \% ; 13 \%$ ee $\quad$ Y: $\quad 99 \% ; 24 \%$ ee

Conditions: $10 \mathrm{~mol} \%$ of the ligand and $5 \mathrm{~mol} \% \mathrm{M}(\mathrm{OTf})_{3}$ were pre-stirred at $60{ }^{\circ} \mathrm{C}(30$ $\mathrm{min})$. Reactions were performed on 0.15 or $0.076 \mathrm{mmol}$ scale in $\mathrm{DCE}\left(\mathrm{Sc}(\mathrm{OTf})_{3}\right)$ at $60{ }^{\circ} \mathrm{C}(0.02 \mathrm{M})$ or benzene $\left(\mathrm{Y}(\mathrm{OTf})_{3}\right)$ at $80{ }^{\circ} \mathrm{C}(0.04 \mathrm{M})$.

formed was monitored by UPLC in 3-minute intervals over 30 minutes. Based on the results obtained, the order in $\mathrm{Y}(\mathrm{OTf})_{3}$ was determined to be 1.02 (Figure 5). In comparison, the scandium-catalyzed reaction proceeding with a slower rate was monitored in 30-minute intervals for 7 hours and the order of the reaction in catalyst was determined to be 0.91 (see Supporting Information for additional 
details on kinetic studies). Taken together, the ${ }^{1} \mathrm{H}-\mathrm{NMR}$ and first-order kinetics ${ }^{22}$ observed in our kinetic studies are consistent with a tetradentate monometallic binding mode 7 for both the scandium- and yttrium-based catalyst systems.

Ligand structure: To further understand the structural elements required to maintain high ee and mediate a reversal of enantioselectivity, we next studied various pyridine-derived ligands (Table 3 ). In comparison to bipyridine $\mathbf{1}$, bidentate and tridentate ligands $\mathbf{9}$ and $\mathbf{1 0}$ failed to form enantiomerically enriched Michael adduct 6 with either Y(OTf) 3 or $\mathrm{Sc}(\mathrm{OTf})_{3}$. These results suggest that the tetradentate binding mode of ligand $\mathbf{1}$ is an important feature for enantioinduction. Similarly, methyl ether ligand 11 resulted in the formation of $\mathbf{6}$ in $0 \%$ ee with both scandium- and yttriumbased Lewis acids, suggesting that the free alcohol moieties are critical for the induction of chirality. More electron-rich methoxy-substituted ligand $\mathbf{1 2}$ afforded higher yields and faster reaction times with minimal loss of enantiomeric excess. We attribute this enhanced reactivity to a more electron-rich metal center upon binding to $\mathbf{1 2}$ leading to a more reactive metal enolate ${ }^{17}$ in both the scandium- and yttriumcatalyzed reactions. Finally, conformationally locked

Figure 6: $\mathrm{Eu}(\mathrm{fod})_{3}$ NMR shift reagent induces chemical shifts of the methyl groups in $\beta$-ketoester substrate 4 .
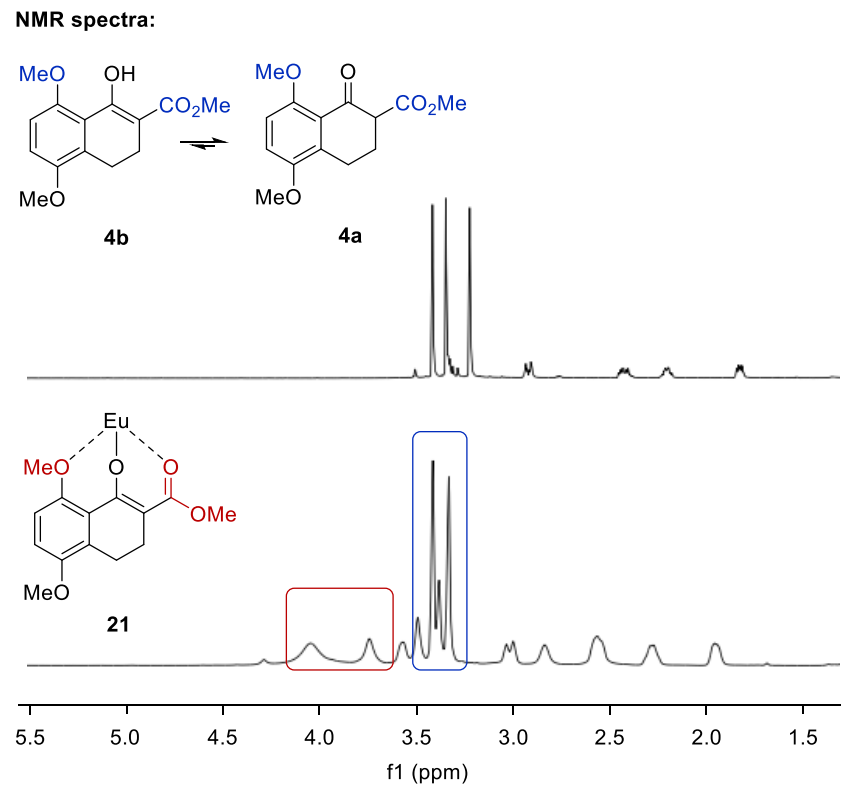

phenanthroline-derived ligand $\mathbf{1 3}$ similarly showed a reversal of enantioselectivity for substrate $\mathbf{6}$. Importantly, unlike ligands 1 and 12, phenanthroline 13 cannot undergo rotation around its central bond, and is unable to bind two equivalents of metal (8, Figure 4). Together with the NMR and kinetic studies, these results suggest that a conformational change in the bipyridine ligand is not responsible for the reversal of enantioselectivity and that both scandium and yttrium metal centers interact with the bipyridine ligand to form a 1:1 metal-ligand complex.

Substrate structure: We next evaluated the effect of the substrate on the reversal of enantioselectivity in asymmetric Michael reactions. Specifically, aromatic $\beta$-ketoester substrates differing in their aromatic substitution pattern were evaluated (Table 4). Importantly, the scandium-catalyzed transformation generally afforded high enantioselectivity
$(6,16-20$, Table 4) which is consistent with the initial report by Kobayashi and coworkers ${ }^{17}$ and demonstrates that the ortho-methoxy substituent is not necessary to achieve high enantioselectivity with this catalytic system. In comparison, the yttrium-catalyzed reaction was generally highyielding, resulting in up to 99\% yield of products 6 and 1620. However, Michael adducts 17 and 19 bearing methoxy substituents in the meta position were formed in low enantiomeric excess of $17 \%$ ee and $13 \%$ ee, respectively. Similarly, para-methoxy substituted indanone $\mathbf{2 0}$ was formed in low enantiomeric excess of $24 \%$, as was the meta, para-substituted dimethoxy product 18 (7\% ee). Interestingly, those substrates containing substitution in the ortho position afforded the desired Michael adducts $(\mathbf{1 6}, \mathbf{6}$, Table 4) in high enantioselectivities of $90 \%$ and $95 \%$. Importantly, for all substrates investigated the major enantiomer formed under the $\mathrm{Y}(\mathrm{OTf})_{3}$-catalyzed reaction conditions was opposite to that formed relying on $\mathrm{Sc}(\mathrm{OTf})_{3}$. To further investigate the unique impact of the ortho substituents, we conducted ${ }^{1} \mathrm{H}-\mathrm{NMR}$ studies relying on Eu(fod) ${ }_{3}$ as an NMR-shift reagent. ${ }^{23}$ Importantly, $\mathrm{Eu}^{3+}$ has an ionic radii of $1.066 \AA$ that is comparable in size to that reported for $\mathrm{Y}^{3+}$ with $1.019 \AA$. Additionally, our initial reaction optimization showed that $\mathrm{Eu}(\mathrm{OTf})_{3}$ resulted in the formation of product 6 with similar yield and enantiomeric excess as $\mathrm{Y}(\mathrm{OTf})_{3}$ (entries 6 and 15, Table 1). When substrate 4 was treated with $\mathrm{Eu}(\mathrm{fod})_{3}$ in $d_{6^{-}}$ benzene two new methoxy signals were observed in the ${ }^{1} \mathrm{H}$ NMR spectrum, which suggests a three-point binding of the substrate to the europium metal center (21, Figure 6). This result is consistent with the hypothesis that the ortho-substituent in the substrate plays an important role in the observed enantiodivergence.

Calculations: To better understand the switch of stereoinduction, we employed DFT calculations. Such techniques have become powerful tools for the mechanistic interrogation of reactions including those catalyzed by Lewis acids. ${ }^{24}$ However, the investigation of the chiral Lewis acid complexes described in this study was projected to involve several additional complications, including the presence of multiple catalytically competent species in solution, which would render the control and interpretation of experimental outcomes difficult. Thus, we aimed to restrict the computational analysis ${ }^{25}$ to the relevant enantiodetermining step in which the stereogenic center is formally set during the Michael addition. Stationary points were located using M06 density functional using a mixed basis set of SDD

Figure 7: Mechanistic considerations for the Michael addition: enantioselectivity can be under kinetic or thermodynamic control.

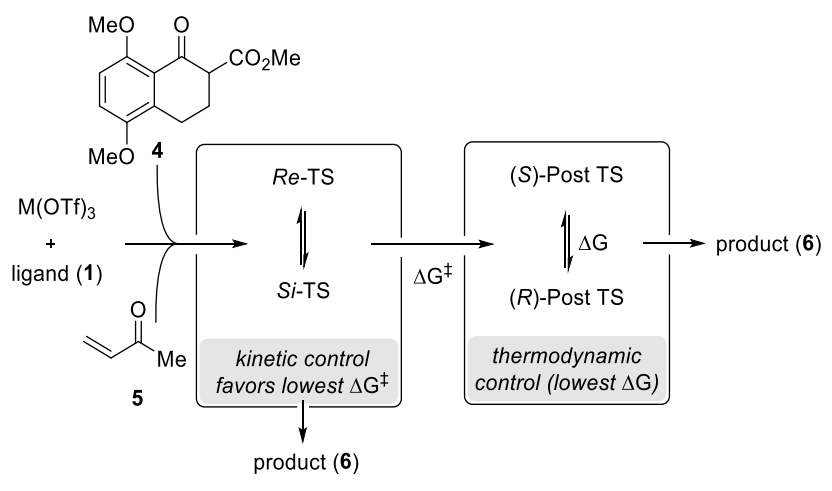


Figure 8: Proposed models for metal-substrate binding and possible facial selectivity in the approach of $\mathbf{5}$.

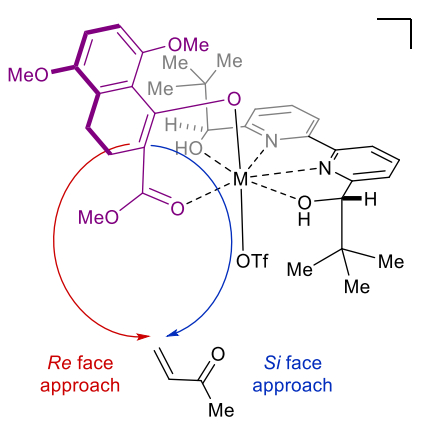

22

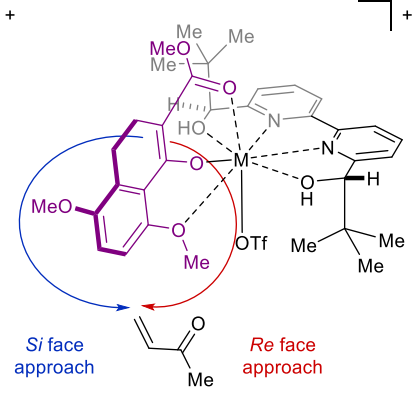

23
Four possible transition state structures to be considered

Figure 9: A. Complexes investigated computationally. B. Lowest energy pathways for each complex relative to the Pre TS complex. $\Delta \mathrm{G}_{\text {int }}$ is the energy difference between Pre TS and Post TS. A negative value implies the Post TS complex is favored.

A. Metal-enolate complexes used for computational analysis.

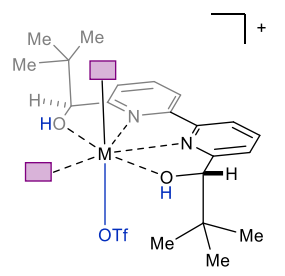

$\mathrm{M}_{\mathrm{L}} \cdot 2 \mathrm{H} \cdot \mathrm{OTf}(\mathbf{2 4})$

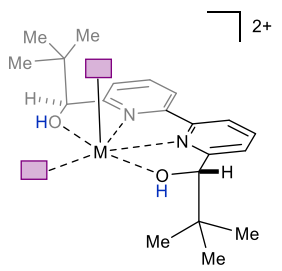

$\mathrm{M}_{\mathrm{L}} \cdot 2 \mathrm{H}(\mathbf{2 7})$

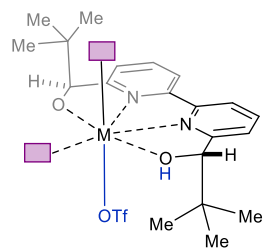

$M_{L} \cdot H \cdot O T f(25)$

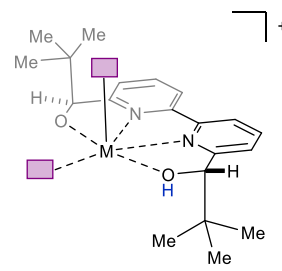

$\mathrm{M}_{\mathrm{L}} \cdot \mathrm{H}(\mathbf{2 8 )}$

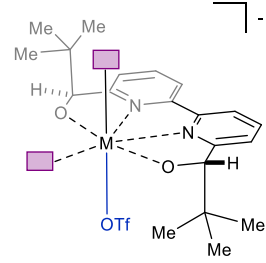

$\mathrm{M}_{\mathrm{L}} \cdot$ OTf (26)

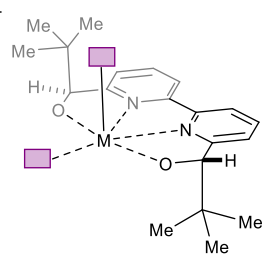

$M_{L}(29)$
B. Summary of lowest energy pathways for each complex relative to Pre-TS complex. All energies reported in $\mathrm{kcal} / \mathrm{mol}$.

\begin{tabular}{|c|c|c|c|}
\hline Catalyst Complex & Gas Phase $\Delta \mathrm{G}^{\ddagger}$ & Solvent Corrected $\Delta \mathrm{G}^{\ddagger}$ & $\Delta \mathrm{G}_{\mathrm{int}}$ \\
\hline $\mathrm{Sc}_{\mathrm{L}} \cdot 2 \mathrm{H} \cdot \mathrm{OTf}(\mathrm{Sc}-24)$ & 22.1 & 20.9 & 2.9 \\
\hline $\mathrm{Sc}_{\mathrm{L}} \cdot \mathrm{H} \cdot \mathrm{OTf}(\mathrm{Sc}-25)$ & 15.7 & 16.7 & 9.0 \\
\hline $\mathrm{Sc}_{\mathrm{L}} \cdot \mathrm{OTf}(\mathrm{Sc}-\mathbf{2 6})$ & 14.0 & 13.3 & 2.5 \\
\hline $\mathrm{Sc}_{\mathrm{L}} \cdot 2 \mathrm{H}(\mathrm{Sc}-27)$ & 19.3 & 17.6 & 5.4 \\
\hline $\mathrm{Sc}_{\mathrm{L}} \cdot \mathrm{H}(\mathrm{Sc}-28)$ & 14.4 & 15.2 & -1.8 \\
\hline $\mathrm{Sc}_{\mathrm{L}}(\mathbf{S c}-29)$ & 18.8 & 20.6 & 6.5 \\
\hline $\mathrm{Y}_{\mathrm{L}} \cdot 2 \mathrm{H} \cdot \mathrm{OTf}(\mathrm{Y}-24)$ & 15.0 & 14.7 & 1.6 \\
\hline$Y_{L} \cdot H \cdot O T f(Y-25)$ & 20.6 & 18.4 & 10.2 \\
\hline$Y_{L} \cdot$ OTf $(Y-26)$ & 15.7 & 15.8 & 3.1 \\
\hline $\mathrm{Y}_{\mathrm{L}} \cdot 2 \mathrm{H}(\mathrm{Y}-27)$ & 18.7 & 17.9 & 7.0 \\
\hline$Y_{L} \cdot H(Y-28)$ & 10.4 & 12.4 & -2.1 \\
\hline$Y_{L}(Y-29)$ & 14.0 & 15.2 & 3.6 \\
\hline
\end{tabular}

for yttrium and 6-31G(d,p) for all other atoms; for scandium the same functional was deployed with the 6-31G(d,p) basis set for all atoms. Single-point energies M06/def2-TZVP were then calculated on these structures. Solvation free energy corrections were computed by means of an IEFPCM model.
Ligand exchange between the bipyridine and triflate can lead to a number of catalytically active species which differ in triflate coordination number and ligand protonation state. By assuming that the ligand bound Lewis acid species are in equilibrium at $60-80^{\circ} \mathrm{C}$, Curtin-Hammett conditions ${ }^{26}$ should apply and, therefore, the favored pathway is determined by the absolute energies of the transition state (TS; kinetic control, Figure 7). ${ }^{27}$ Intriguingly, the low barriers calculated for the achiral pathways $\left(13.1\right.$ and $14.4 \mathrm{kcal} \mathrm{mol}^{-}$ 1 for scandium and yttrium, respectively) suggest that since such high levels of enantioselectivity are achieved, ligand complexation to metal is irreversible ${ }^{25}$. This indicates that the achiral Lewis acid species do not participate in the reaction. In addition to a kinetically controlled pathway, we also considered the possibility that enantioselectivity could arise from equilibration of the resulting diastereoisomeric, post-TS Lewis acid complexes. In this case, the most stable structure following C-C bond formation between $\mathbf{4}$ and $\mathbf{5}$ leads to the product (thermodynamic control, Figure 7). The key stationary points important for explaining enantioselectivity are shown in Figure 11 and are referenced throughout this discussion.

We first considered the possibility that product distribution is determined by the kinetics of the C-C bond formation. Complex $\mathbf{M}_{\mathrm{L} .2 H .0 T f}$ (24), proposed by Kobayashi, ${ }^{17}$ was initially investigated as the catalytically active species. The enolate can orient itself with respect to the catalyst in one of two ways: the aromatic group can be directed away from (22) or toward (23) the triflate as shown in Figure 8. Additionally, substrate $\mathbf{5}$ can approach from the front or the back. Combining these considerations, four classes of TS are formulated for this catalytic species (Figure 8). In addition to $\mathbf{M}_{\mathrm{L}}$.2H.OTf (24), we considered other catalytic species which varied in triflate coordination number and protonation state (partially or fully deprotonated) of the bound bipyridine ligand. This leads to a total of six catalyst complexes (24-29, Figure 9A).

Scandium: Our initial calculations with $\mathbf{S c}_{\mathrm{L}}$.2H.OTf (Sc-24) determined the lowest-energy transition state for the scandium-catalyzed reaction to be $\mathbf{T S} \mathbf{1}_{\mathbf{s c}}-\mathbf{S i}$, having an activation free energy of $20.9 \mathrm{kcal} \mathrm{mol}^{-1}$ (Figure 9B). This pathway was found to be $0.7 \mathrm{kcal} \mathrm{mol}^{-1}$ lower in energy than that leading to the competing product, $\mathbf{T S} \mathbf{1}_{\mathbf{s c}}-\mathbf{R e}$. This preference can be attributed to the increased Lewis acidity of the scandium which arises from a twisting of the bipyridine ligand (NCCN dihedral $\mathbf{T S} \mathbf{1}_{\mathbf{S c}}-\mathbf{S i}$ is $\mathbf{1 6 . 0}$ and $\mathbf{T S} \mathbf{1}_{\mathbf{s c}}-\mathbf{R e}$ is 12.3) and stronger $\mathrm{H}$-bonding contacts with the ketone substrate for $\mathbf{T S} \mathbf{1}_{\mathbf{s c}} \mathbf{- S i}$. However, the computed enantioselectivity from this pathway was found to be $-48 \%$ ee which is much lower than that observed ( $-90 \%$ ee). It is therefore possible that the other

Figure 10: Lewis and Brønsted acid modes of activation of $\mathbf{5}$ using 24 as an example.
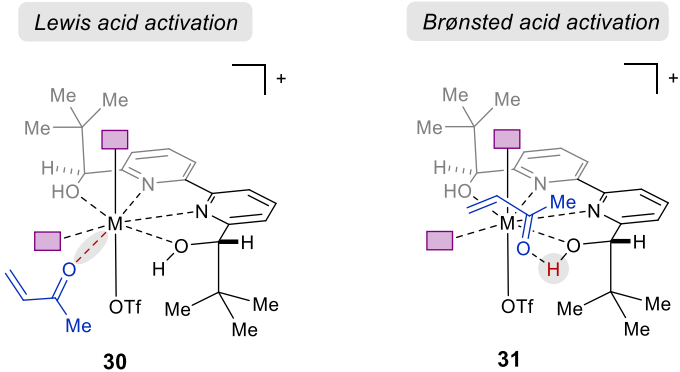


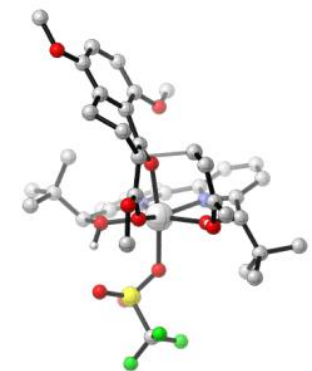

TS1 $1_{\mathrm{Sc}}-\mathrm{Si}: \Delta \mathrm{G}^{\ddagger}=+20.9 \mathrm{kcal} / \mathrm{mol}$

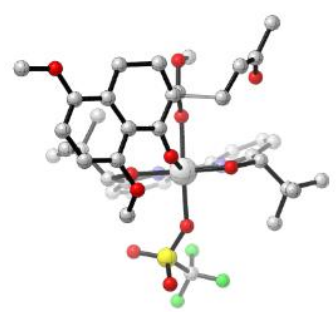

$\mathrm{TS}_{\mathrm{Sc}}-\mathrm{Re}: \Delta \mathrm{G}^{\ddagger}=+13.3 \mathrm{kcal} / \mathrm{mol}$

B. Yttrium

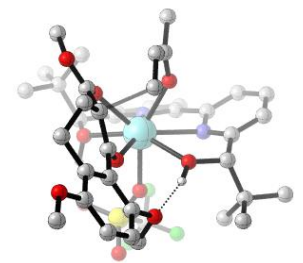

TS1 $1-\operatorname{Re}: \Delta G^{\ddagger}=+14.7 \mathrm{kcal} / \mathrm{mol}$

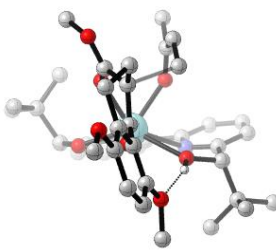

TS3 ${ }_{Y}-\operatorname{Re}: \Delta \mathbf{G}^{\ddagger}=+12.4 \mathrm{kcal} / \mathrm{mo}$

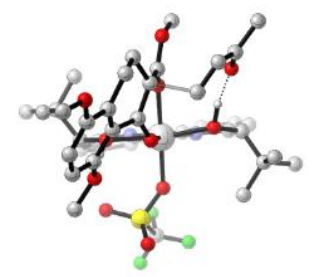

TS1 ${ }_{\mathrm{Sc}}-\operatorname{Re}: \Delta \mathrm{G}^{\ddagger}=+21.6 \mathrm{kcal} / \mathrm{mol}$

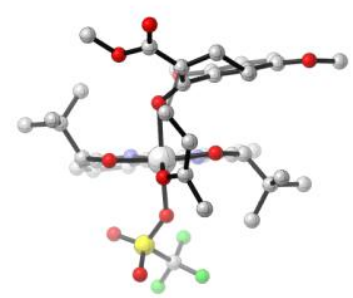

$\mathrm{TS}_{\mathrm{Sc}}-\mathrm{Si}: \Delta \mathrm{G}^{\ddagger}=+16.3 \mathrm{kcal} / \mathrm{mol}$

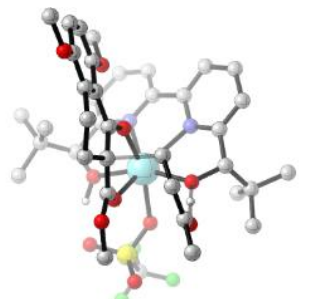

TS1 $1_{Y}-\mathrm{Si}: \Delta \mathbf{G}^{\ddagger}=+17.3 \mathrm{kcal} / \mathrm{mol}$

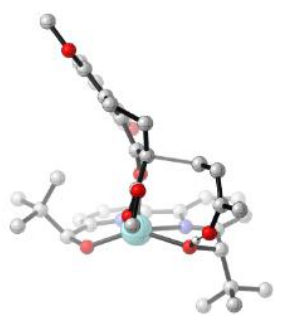

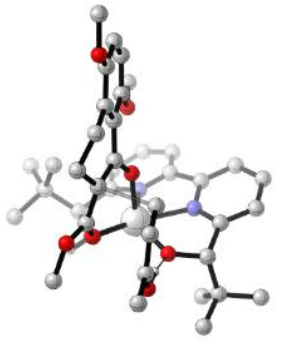

$\mathrm{TS}_{\mathrm{Sc}}-\mathrm{Si}: \Delta \mathrm{G}^{\ddagger}=+17.6 \mathrm{kcal} / \mathrm{mol}$

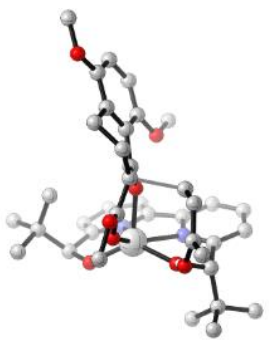

$\mathrm{TS} 4_{\mathrm{Sc}}-\mathrm{Si}: \Delta \mathrm{G}^{\ddagger}=+15.2 \mathrm{kcal} / \mathrm{mol}$

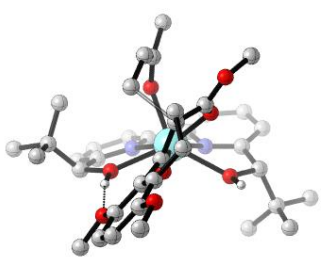

TS2 $\mathrm{Y}-\mathrm{Si}: \Delta \mathrm{G}^{\ddagger}=+17.9 \mathrm{kcal} / \mathrm{mol}$

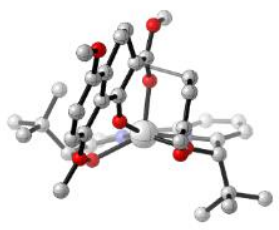

$\mathrm{TS}_{\mathrm{Sc}}-\mathrm{Re}: \Delta \mathrm{G}^{\ddagger}=+\mathbf{2 0} .4 \mathrm{kcal} / \mathrm{mol}$

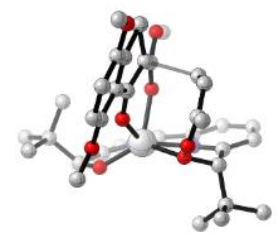

$\mathrm{TS}_{\mathrm{Sc}}-\mathrm{Re}: \Delta \mathrm{G}^{\ddagger}=+18.3 \mathrm{kcal} / \mathrm{mol}$

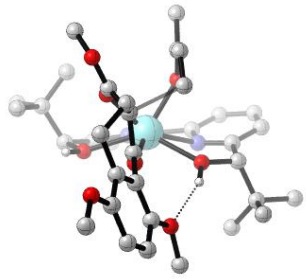

TS2 $Y-\operatorname{Re}: \Delta G^{\ddagger}=+18.6 \mathrm{kcal} / \mathrm{mol}$
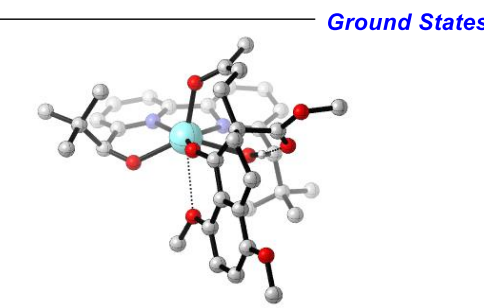

S-Product: $\Delta \mathbf{G}=-2.1 \mathrm{kcal} / \mathrm{mol}$
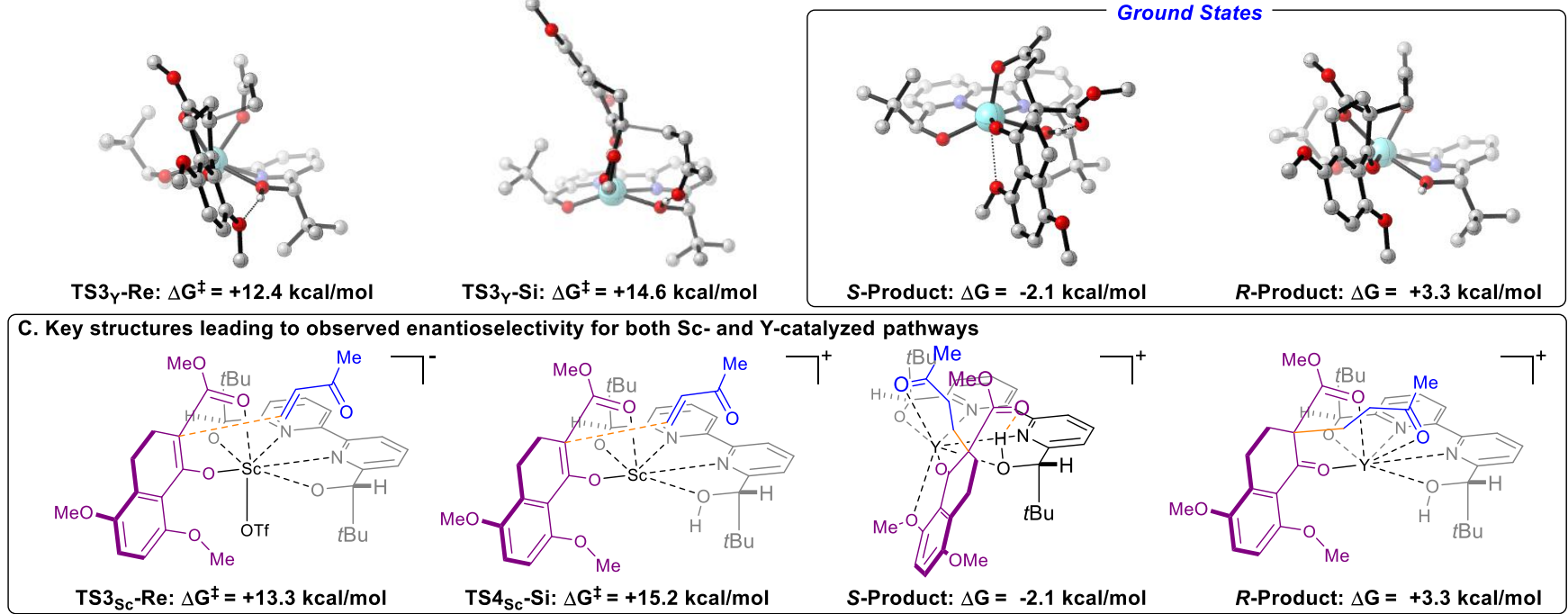

Figure 11. Key TS for A. the scandium-catalyzed Michael additions and B. selected transition states for the yttrium-catalyzed Michael addition as well as the key post-TS complexes leading to thermodynamic control of enantioselectivity. C. 2D representations of the structures determined to be active in the enantiodetermining step of the respective reactions. Geometries were obtained from M06/6-31G(d,p) with the SDD ECP applied for the Y atom when applicable. Single point energies from M06/def2TZVP with the IEFPCM solvation model.

catalytic species outlined in Figure 9A could promote lower energy pathways. Importantly, in these preliminary studies, we identified two possible modes of bifunctional activation (Figure 10) in which the catalyst can interact with both the nucleophile (4) and electrophile (5): 1) a Lewis acid mediated mechanism, in which the carbonyl of $\mathbf{5}$ is activated by direct coordination with the metal center (30), and 2) a
Brønsted acid type mechanism in which substrate $\mathbf{5}$ is activated by hydrogen bonding between the carbonyl and the hydroxy protons of the metal-ligand complex (31). Other modes of activation such as mono-activation mechanisms in which only the enolate (4) binds to the catalyst were also located. 

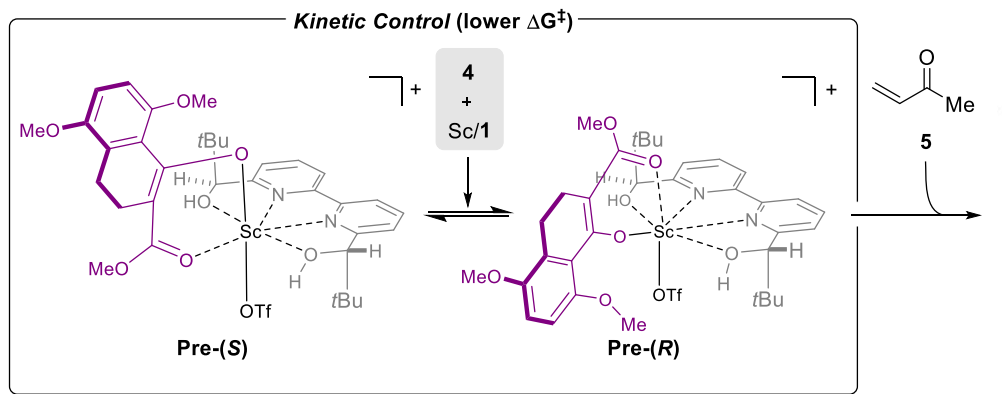

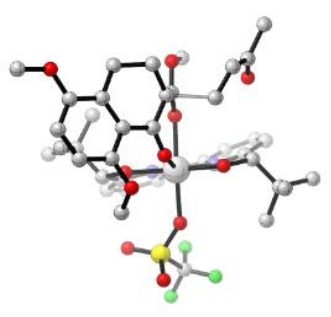

TS ${ }_{S c}-\operatorname{Re}: \Delta G^{\ddagger}=+13.3 \mathrm{kcal} / \mathrm{mol}$

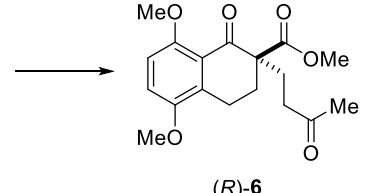

calculated ee: $89 \%$ favoring $(R)-6$ observed ee: $90 \%$ favoring $(R)-6$

B. Yttrium-Pathway: Thermodynamically controlled (equilibration of Post TS-complexes leads to more stable (S)-enantiomer

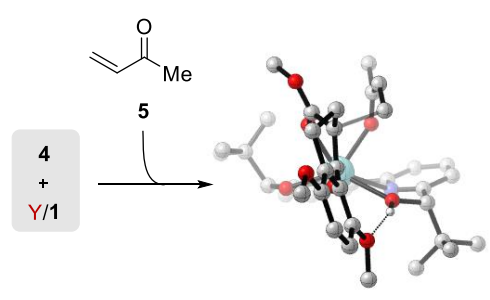

TS3 ${ }_{Y}-\operatorname{Re}: \Delta \mathbf{G}^{\ddagger}=+12.4 \mathrm{kcal} / \mathrm{mol}$

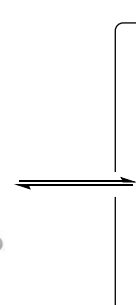

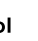

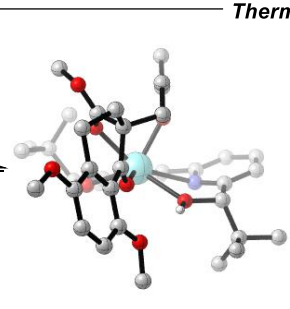

(R)-Post TS: $\Delta \mathbf{G}=+3.3 \mathrm{kcal} / \mathrm{mol}$

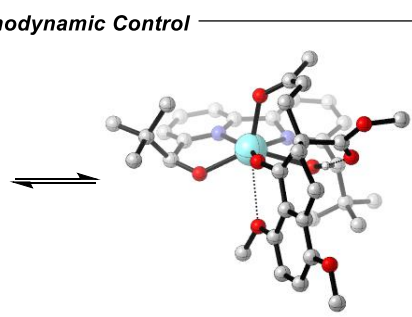

(S)-Post TS: $\Delta G=-2.1 \mathrm{kcal} / \mathrm{mol}$

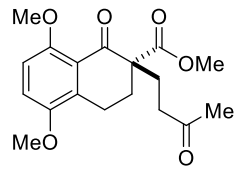

(S)-6

calculated ee: $>99 \%$ favoring $(S)-6$ observed ee: $95 \%$ favoring $(S)-6$

Figure 12. Summary of the calculated controlling features of the metal-dependent enantiodivergence. A. the scandium-catalyzed pathway proceeds through the lowest activation barrier (kinetic control) to afford $(R)-\mathbf{6}$ while B. coordination of the orthomethoxy substituent leads to a thermodynamic preference for $(S)-6$ in a post-TS equilibrium of Y-complexes.

Considering the TS possibilities with $\mathbf{S c}_{\mathbf{L}} \mathbf{2 H}$ (Sc-27; Figure 11A), we next identified $\mathbf{T S} \mathbf{2}_{\mathbf{S c}} \mathbf{- S i}$ as the lowest energy TS for this complex. The activation energy was calculated to be $\mathbf{1 7 . 6} \mathrm{kcal} \mathrm{mol}^{-1}$, which is lower than $\mathbf{T S} \mathbf{1}_{\mathbf{s c}}-\mathbf{S i}$ and corresponds to a second Brønsted acid type mechanism (Figure 10). However, if this were the active catalytic species in solution, formation of the $S$ product is expected while the $R$ enantiomer was preferred experimentally. Therefore, our calculations suggest that neither of these catalytic species are likely to be responsible for the experimental outcome. Next, we exhaustively considered the other species with deprotonated ligands. Our calculations determined that for scandium, the lowest-energy TS corresponds to a $\mathbf{S c}_{\mathrm{L}}$.OTf

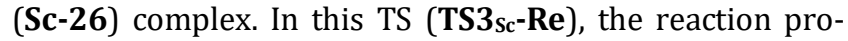
ceeds via a Lewis acid type activation mode in which only the enolate is activated. Furthermore, the combination of a twisted bipyridine that reduces the binding interaction to the metal and a coordinated triflate leads to a higher Lewis acidity relative to the other species involved. The preference for $\mathbf{T S} \mathbf{3}_{\mathbf{s c}}-\mathbf{R e}$ over $\mathbf{T S} \mathbf{3}_{\mathbf{S c}}-\mathbf{S i}$ can be attributed to a reduction in favorable acid-base contacts between the scandium and the enolate in the latter. However, our calculations holistically suggest that the lowest energy pathway leading to the opposite enantiomer proceeds via $\mathbf{T S 4} \mathbf{s c}-\mathbf{S i}$ (Figure 11A) involving a Sc $\mathbf{C}_{\mathbf{L}} \mathbf{. H}$ (Sc-28) complex. When comparing the calculated lowest-energy pathway leading to the $S$ and $R$ enantiomer (those proceeding through $\mathbf{T S} \mathbf{S s c}_{\mathbf{S c}}-\mathbf{S i}$ and TS3sc-Re, respectively), the computed enantioselectivity is $-89 \%$ ee, which is in very good agreement to observed experimental value of $-90 \%$ ee (Figure 12A). Although, in this catalytic mode of activation (TS4sc-Si) the catalyst complex simultaneously activates both electrophile and nucleophile, the Lewis acid catalysis of $\mathbf{S c}_{\mathrm{L}}$.OTf (Sc-26) is more effective than the Brønsted acid catalysis of $\mathbf{S c}_{\mathbf{L}} \mathbf{. H}$ (Sc-27) leading to a reduction in the activation energy for $\mathbf{T S} \mathbf{3}_{\mathbf{S c}}-\mathbf{R e}$ and the high levels of enantioselectivity observed. The lack of interaction between the complex and the substrate's OMe substituent implies that selectivity will not be sensitive to structural modifications at this position, which agrees with our observations for the scandium-catalyzed system (Table 4). The diastereomeric post-TS product complexes, formed after $\mathrm{C}-\mathrm{C}$ bond formation, were also located. These calculations demonstrated that if the reaction were to be under thermodynamic control, the $S$ product would be observed in high levels of selectivity. The reversibility of the addition would depend on the barrier for protonation, yet, the investigation of such steps is often intractable by computation. The good agreement between experiment and computation suggests that this step is fast and the product distribution is determined by the kinetics of $\mathrm{C}$-C bond formation. Moreover, we found that experimentally increasing the temperature of the reaction led to lower levels of enantioselectivity, ${ }^{28}$ consistent with a kinetically controlled reaction. The small activation energies for the addition suggest other factors could contribute to the low yield of the scandium reaction pathway for some substrates (e.g. enolate formation).

Yttrium: Next, we computed the possible pathways for the yttrium-catalyzed system. As before, we began by investigating the $\mathbf{Y}_{\mathrm{L}}$.2H.OTf (Y-24; Figure 11B) as the active catalytic species. In these TS, the larger ionic radius of yttrium renders the Lewis acid activation of substrate $\mathbf{5}$ the lowest energy TS pathway. The activation free energy was calculated to be $14.7 \mathrm{kcal} \mathrm{mol}^{-1}$. A comparison of the lowest energy $\mathbf{T S}, \mathbf{T S} \mathbf{1}_{\mathbf{Y}}-\mathbf{R e}$ and $\mathbf{T S} \mathbf{1}_{\mathbf{Y}}-\mathbf{S i}$, indicates that the reaction should proceed to give $R$ product, whereas the $S$ enantiomer was obtained experimentally. Therefore, we next considered the reaction catalyzed by $\mathbf{Y}_{\mathrm{L} . \mathbf{2}} \mathbf{H}(\mathbf{Y}-\mathbf{2 7})$, which excludes triflate coordination to the metal. Comparison of activation 
barriers precludes the analogous yttrium species as the active catalyst (17.9 kcal mol-1 Figure 9B). Therefore, our calculations suggest that neither of these catalysts are likely to be responsible for the experimental outcome. In considering the other complexes, we determined that the computed enantioselectivity that arises from these complexes would be high but lead to the $R$ product (computed ee is $-93 \%$ ). Therefore, a kinetically controlled $\mathrm{C}-\mathrm{C}$ bond forming reaction could not explain the high levels of enantioselectivity observed in these complexes. It is possible that thermodynamic control over the equilibration of the resulting diastereoisomeric yttrium complexes yields enantiomerically enriched products. The lowest energy diastereomeric product complexes, formed after C-C bond formation, were calculated to be within $5.4 \mathrm{kcal} \mathrm{mol}^{-1}$ of each other (Figure 11B), with the $S$ structure the lowest in energy. Therefore, very high levels of enantioselectivity are expected in this system if the reaction were to be under thermodynamic control (calculated $>99 \%$ ee). While the energy difference is overestimated, the reproduction of experimental enantioselectivity trends - that yttrium is calculated to promote the reaction with higher levels of enantioselectivity compared to scandium - illustrates the strength of the computational analysis. The reason for the strong preference for the $S$ product is due to the generation of a Lewis acid-base interaction with the methoxy group and the yttrium metal center (Figure 10). The lack of such a stabilizing interaction would increase the energy of the ground state complex that leads to $S$ product relative to the $R$ and thus result in low levels of enantioselectivity. This is in good agreement with the structure selectivity relationships shown in Table 4. Conversely to the scandium-catalyzed reaction, we found that experimentally increasing the temperature of the reaction led to higher levels of enantioselectivity, consistent with a thermodynamically controlled reaction. Remarkably, the two Lewis acid complexes bearing the same chiral ligand do not give the same enantiomeric products as a result of a complex interplay of kinetic and thermodynamic control (Figure 12).

Model for enantiodivergence: Based on our combined results revealing the importance of a Lewis basic substituent in the ortho-position of the substrate, mechanistic studies supporting a tetradentate metal-ligand binding mode in a monometallic system, and computational analysis, we propose a distinct model explaining the reversal of enantioselectivity (Figure 12). Importantly, the change in central metal leads to a distinct coordination environment: specifically, the larger yttrium metal can interact with a greater number of Lewis bases. As a result, two different reactive conformations for the metal-ligand-substrate complex are possible (Figure 8). In the case of the smaller scandium metal center, the substrate interacts with the metal-ligand complex upon two-point binding (22) in the lowest energy structures. This is similar to the metal-ligand binding proposed by Kobayashi and coworkers in their initial studies of the $\mathrm{Sc}(\mathrm{OTf})_{3}-\mathbf{1}$ catalyzed Michael addition. ${ }^{17}$ Our computational analysis confirmed that the lowest energy transition state (TS3 ${ }_{\text {Sc }}-\mathbf{R e}$ ) is expected to result in enantiomeric excess consistent with our experimental observations. When employing the larger yttrium metal as Lewis acid, NMR studies (Figure 6) suggest that the Lewis basic ortho substit- uent of the substrate also binds to the metal, which must induce a 180-degree rotation of the substrate (23, Figure 8). Computational analysis revealed that this reaction is under thermodynamic control and the effect of the ortho-substituent impacts the stability of the post-TS complex. Calculated and measured ee values are again in good agreement (Figure 12B). Importantly, substrate-dependent binding to chiral metal catalysts has been previously described to explain differences in enantioselectivity between substrates. ${ }^{29}$ However, these specific substrate-metal complex interactions have not been observed to result in a complete reversal of enantioselectivity depending on the choice of metal catalyst. While a number of previous reports ${ }^{6-9,14-15}$ have observed metal-dependent enantiodivergence, reliance on an additional Lewis basic site of the reactive substrate has not previously been suggested as a rationale for such a reversal. In this system, the choice of metal influences the coordination environment of the metal-ligand complex while the active participation of a Lewis basic site in the substrate is critical to induce the observed reversal of enantioselectivity. The insights obtained herein are particularly important in the future design of enantiodivergent catalysis - namely the importance of considering the participation of the substrate.

Conclusions: Our observation of metal-dependent reversal of enantioselectivity for this conjugate addition reaction has been optimized for scandium and yttrium with bipyridine ligand 1 and studied extensively. Through non-linear effect and kinetic studies, we have determined that the mechanism relies a 1:1 complex of ligand and metal. Additionally, we have shown the importance of the $\mathrm{C}_{2}$ symmetry and the free hydroxy groups in ligand $\mathbf{1}$ as well as the necessity of an ortho substituent in the substrate to afford high enantioselectivity in the yttrium-catalyzed reaction. Finally, computational modeling illustrates kinetic control of selectivity in the scandium-catalyzed pathway in contrast to a more complex, thermodynamically driven enantioselectivity induced by the presence of the ortho substituent in the yttrium-based system. These studies will serve to aid in the future development of enantiodivergent catalytic methods relying only on a change in the identity of metal catalyst.

\section{ASSOCIATED CONTENT}

\section{Supporting Information.}

The Supporting Information, containing supplemental figures, detailed experimental procedures and characterization data for all new compounds is available free of charge on the ACS publications website at http://pubs.acs.org.

\section{AUTHOR INFORMATION}

\author{
Corresponding Author \\ * Email: corinnas@umich.edu \\ * Email: jolenereid43@gmail.com
}

\section{ORCID}

Paul S. Riehl: 0000-0003-3810-1627

Jolene P. Reid: 0000-0003-2397-0053

Corinna S. Schindler: 0000-0003-4968-8013 


\section{Author Contributions}

The manuscript was written through contributions of all authors.

\section{Funding Sources}

The authors thank the NIH/National Institute of General Medical Sciences (R01-GM118644), the Alfred P. Sloan Foundation, the David and Lucile Packard Foundation, and the Camille and Henry Dreyfus Foundation for financial support. P.S.R. thanks the Rackham Graduate School and Eli Lilly for graduate research fellowships. J.P.R. thanks the EU Horizon 2020 Marie Skłodowska-Curie Fellowship (grant no. 792144). Computational resources were provided from the Center for High Performance Computing (CHPC) at the University of Utah and the Extreme Science and Engineering Discovery Environment (XSEDE), which is supported by the NSF (ACI-1548562) and provided through allocation TG-CHE190020.

\section{ACKNOWLEDGMENTS}

We gratefully acknowledge Prof. James Devery (Loyola University Chigaco) for helpful discussion regarding kinetic analysis and Prof. Nathaniel Szymczak (University of Michigan) for helpful discussion regarding NMR experiments.

\section{REFERENCES}

(1) Jacobsen, E.; Pfaltz, A.; Yamamoto, H. Comprehensive asymmetric catalysis; Springer: London, 2003.

(2) Pfaltz, A.; Drury, W. J. Design of Chiral Ligands for Asymmetric Catalysis: From C2-Symmetric P,P- and N,N-Ligands to Sterically and Electronically Nonsymmetrical P,N-Ligands. PNAS 2004, 101 (16), 5723-5726.

(3) Paquette, L. Chiral reagents for asymmetric synthesis; Wiley: Chichester, 2008.

(4) Kim, Y.H. Dual Enantioselective Control in Asymmetric Synthesis. Acc. Chem. Res. 2001, 34, 955-962.

(5) For excellent reviews of the topic of enantiodivergence, see a) Ref. 4; b) Sibi, M.; Liu, M. Reversal of Stereochemistry in Enantioselective Transformations. Can they be Planned or are the Just Acciddental Curr. Org. Chem. 2001, 5, 719-755; c) Zanoni, G.; Castronovo, F.; Franzini, M.; Vidari, G.; Giannini, E. Toggling enantioselective catalysis - a promising paradigm in the development of more efficient and versatile enantioselective synthetic methodologies. Chem. Soc. Rev. 2003, 32, 115-119; d) Tanaka, T.; Hayashi, M. New Approach for Complete Reversal of Enantioselectivity Using a Single Chiral Source. Synthesis 2008, 21, 3361-3376; e) Bartók, M. Unexpected Inversions in Asymmetric Reactions: Reactions with Chiral Metal Complexes, Chiral Organocatalysts, and Heterogeneous Chiral Catalysts. Chem. Rev. 2010, 110, 1663-1705; f) Escorihuela, J.; Burguete, M.I.; Luis, S.V. New advances in dual stereocontrol for asymmetric reactions. Chem. Soc. Rev. 2013, 42, 5595-5617; g) Zhan, G.; Du, W.; Chen, Y.-C. Switchable divergent asymmetric synthesis via organocatalysis. Chem. Soc. Rev. 2017, 46, 1675-1692; h) Cao, W.; Feng, X.; Liu, X. Reversal of enantioselectivity in chiral metal complex-catalyzed asymmetric reactions. Org. Biomol. Chem. 2019, 17, 6538-6550.

(6) For select examples using distinct metals, see: a) Desimoni, G.; Faita, G.; Guala, M.; Pratelli, C. Different Lanthanide Ions and the Pybox Substituents Induce the Reverse of the Sense of Induction in the Enantioselective Diels-Alder Reaction between Acryloyloxazolidinone and Cyclopentadiene. J. Org. Chem. 2003, 68, 7862-7866; b) Desimoni, G.; Faita, G.; Guala, M.; Laurenti, A. Synergistic Effect of Pybox Substituents and Lanthanide Cations in Reversing the Asymmetric Induction in the Catalysed Diels-Alder Reaction between 3-Acryloyl-1,3-oxazolidin-3-one and Cyclopentadiene. Eur. J. Org. Chem. 2004, 2004, 30573062; c) Desimoni, G.; Faita, G.; Guala, M.; Laurenti, A.; Mella, M. A New Pyridine-2,6-bis(oxazoline) for Efficient and Flexible Lanthanide-Based Catalysts of Enantioselective Reactions with 3-Alkenoyl-2-oxazolidinones. Chem. Eur. J. 2005, 11, 38163824; d) Kokubo, M.; Naito, T.; Kobayashi, S. Metal-controlled Reversal of Enantioselectivity in Catalyzed Asymmetric Ringopening Reactions of meso-Epoxides in Water. Chem. Lett. 2009, 38, 904-905; e) Kim, H.Y.; Shih, H.-J.; Knabe, W.E.; Oh, K. Reversal of Enantioselectivity between the Copper(I)- and Silver(I)-Catalyzed 1,3-Dipolar Cycloaddition Reactions Using a Brucine-Derived Amino Alcohol Ligand. Angew. Chem. Int. Ed. 2009, 48, 7420-7423; f) Sasaki, S.; Yamauchi, T.; Higashiyama, K. Dy(OTf) $)_{3} /$ Pybox-catalyzed enantioselective Friedel-Crafts alkylation od indoles with $\alpha, \beta$-unsaturated trifluoromethyl ketones. Tet. Lett. 2010, 51, 2326-2328; g) Mazumder, S.; Crandell, D.W.; Lord, R.L.; Baik, M.-H. Switching the Enantioselectivity in Catalytic [4+1] Cycloadditions by Changing the Metal Center: Principles of Inverting the Stereochemical Preference of an Asymmetric Catalysis Revealed by DFT Calculations. J. Am. Chem. Soc. 2014, 136, 9414-9423; h) Rout, S.; Das, A.; Singh, V.K. Metal-Controlled Switching of Enantioselectivity in the Mukaiyama-Michael Reaction of $\alpha, \beta$-Unsaturated 2-Acyl Imidazoles Catalyzed by Chiral Metal-Pybox Complexes. J. Org. Chem. 2018, 83, 5058-5071

(7) a) Ding, Z.-Y.; Chen, F.; Qin, J.; He, Y.-M.; Fan, Q.-H. Asymmetric Hydrogenation of 2,4-Disubstituted 1,5-Benzodiazepines Using Cationic Ruthenium Diamine Catalysts: An Unusual Achiral Counteranion Induced Reversal of Enantioselectivity. Angew. Chem. Int. Ed. 2012, 51, 5706-5710. b) Wang, D.; Cao, P.; Wang, B.; Jia, T.; Lou, Y.; Wang, M.; Liao, J. Copper(I)-Catalyzed Asymmetric Pinacolboryl Addition of N-Boc-Imines Using a Chiral Sulfoxide-Phosphine Ligand. Org. Lett. 2015, 17, 2420-2423. c) Jian, L.; Yan, Q.; Jinpei, C.; Sanzhong, L. Counteranions of In(III) Induced Reversal of Enantiocontrol in Friedel-Crafts Reaction of Indoles by Asymmetric Binary Acid Catalysis. Acta Chimica Sinica 2014, 72, 809.

(8) a) Chen, G.; Gui, J.; Li, L.; Liao, J. Chiral Sulfoxide-Olefin Ligands: Completely Switchable Stereoselectivity in Rhodium-Catalyzed Asymmetric Conjugate Additions. Angew. Chem.Int. Ed.2011, 50, 7681-7685. b) Zhang, Y.; Yang, N.; Liu, X.; Guo, J.; Zhang, X.; Lin, L.; Hu, C.; Feng, X. Reversal of Enantioselective FriedelCrafts C3-Alkylation of Pyrrole by Slightly Tuning the Amide Units of N,N'-Dioxide Ligands. Chem. Commun. 2015, 51, 84328435. c) Harvey, J. S.; Malcolmson, S. J.; Dunne, K. S.; Meek, S. J.; Thompson, A. L.; Schrock, R. R.; Hoveyda, A. H.; Gouverneur, V. Enantioselective Synthesis of P-Stereogenic Phosphinates and Phosphine Oxides by Molybdenum-Catalyzed Asymmetric Ring-Closing Metathesis. Angew. Chem. Int. Ed. 2009, 48, 762766. d) Hirose, T.; Sugawara, K.; Kodama, K. Switching of Enantioselectivity in the Catalytic Addition of Diethylzinc to Aldehydes by Regioisomeric Chiral 1,3-Amino Sulfonamide Ligands. J. Org. Chem. 2011, 76 , 5413-5428. e) Shibata, N.; Yoshimura, M.; Yamada, H.; Arakawa, R.; Sakaguchi, S. Hydroxy-Amide Functionalized Azolium Salts for $\mathrm{Cu}$-Catalyzed Asymmetric Conjugate Addition: Stereocontrol Based on Ligand Structure and Copper Precatalyst. J. Org. Chem. 2012, 77, 4079-4086.

(9) For solvent-dependent reversal of enantioselectivity, see: a) Abadie, M.-A.; Trivelli, X.; Medina, F.; Duhal, N.; Kouach, M.; Linden, B.; Génin, E.; Vandewalle, M.; Capet, F.; Roussel, P.; et al. Gold(I)-Catalysed Asymmetric Hydroamination of Alkenes: A Silver- and Solvent-Dependent Enantiodivergent Reaction. Chem. Eur. J. 2017, 23, 10777-10788. b) Yu, H.; Xie, F.; Ma, Z.; Liu, Y.; Zhang, W. The Effects of Solvent on Switchable Stereoselectivity: Copper-Catalyzed Asymmetric Conjugate Additions Using D2-Symmetric Biphenyl Phosphoramidite Ligands. Org. Biomol. Chem. 2012, 10 (26), 5137-5142. c) Haddad, N.; Qu, B.; Rodriguez, S.; van der Veen, L.; Reeves, D. C.; Gonnella, N. C.; Lee, H.; Grinberg, N.; Ma, S.; Krishnamurthy, D.; et al. Catalytic Asymmetric Hydrogenation of Heterocyclic Ketone-Derived 
Hydrazones, Pronounced Solvent Effect on the Inversion of Configuration. Tet. Lett. 2011, 52, 3718-3722. d) Arseniyadis, S.; Valleix, A.; Wagner, A.; Mioskowski, C. Kinetic Resolution of Amines: A Highly Enantioselective and Chemoselective Acetylating Agent with a Unique Solvent-Induced Reversal of Stereoselectivity. Angew. Chem. Int. Ed. 2004, 43 (25), 3314-3317. For temperature-dependent reversal of enantioselectivity, see: e) Méndez, I.; Rodríguez, R.; Polo, V.; Passarelli, V.; Lahoz, F. J.; García-Orduña, P.; Carmona, D. Temperature Dual Enantioselective Control in a Rhodium-Catalyzed Michael-Type FriedelCrafts Reaction: A Mechanistic Explanation. Chem. Eur J. 2016, 22, 11064-11083. f) Storch, G.; Trapp, 0. Temperature-Controlled Bidirectional Enantioselectivity in a Dynamic Catalyst for Asymmetric Hydrogenation. Angew. Chem.Int. Ed. 2015, 54, 3580-3586. g) Wang, S.; Xiao, J.; Li, J.; Xiang, H.; Wang, C.; Chen, X.; Carter, R. G.; Yang, H. Discovery of Temperature-Dependent, Autoinductive Reversal of Enantioselectivity: Palladium-Mediated [3+3]-Annulation of 4-Hydroxycoumarins. Chem. Commun. 2017, 53, 4441-4444. h) Matusmoto, A.; Fujiwara, S.; Hiyoshi, Y.; Zawatzky, K.; Makarov, A. A.; Welch, C. J.; Soai, K. Unusual Reversal of Enantioselectivity in the Asymmetric Autocatalysis of Pyrimidyl Alkanol Triggered by Chiral Aromatic Alkanols and Amines. Org. Biomol. Chem. 2017, 15, 555-558.

(10) Riehl, P. S.; Richardson, A. D.; Sakamoto, T.; Schindler, C. S. 8Step Enantiodivergent Synthesis of (+)- and (-)-Lingzhiol. Org. Lett. 2020, 22, 290-294.

(11) Lewis Acids in Organic Synthesis; Yamamoto, H., Eds.; WileyVCH: Weinheim, 2000; Vol. 1.

(12) Santelli, M.; Pons, J.-M. Lewis Acids and Selectivity in Organic Synthesis; CRC Press: Boca Raton, FL; 1996.

(13) Selectivities in Lewis Acid Promoted Reactions; Schinzer, D., Eds.; NATO ASI Series C; Kluwer Academic Publishers: Norwell, MA, 1989.

(14) Carlson, R.; Lundstedt, T.; Nordahl, Å.; Prochazka, M. Lewis Acids in Organic Synthesis. Approach to a Selection Strategy for Screening Experiments. Acta Chemica Scandinavica B 1986, 40, $522-533$

(15) Enantiodivergence with this ligand has been previously observed in the ring opening of meso-epoxides relying on copper and scandium as central metals. For details, see Ref. 6d. For a recent example of Sc- and Y-mediated enantiodivergence involving hydrogen bonding solvent effects, see: a) Wang, Z.; Yang, Z.; Chen, D.; Liu, X.; Lin, L.; Feng, X. Highly Enantioselective Michael Addition of Pyrazolin-5-Ones Catalyzed by Chiral Metal/N,N'-Dioxide Complexes: Metal-Directed Switch in Enantioselectivity. Angew. Chem. Int. Ed. 2011, 50, 4928-4932. For a recent example of diastereodivergent Sc- and Y-catalyzed reaction, see b) Cong, X.; Zhan, G.; Mo, Z.; Nishiura, M.; Hou, Z. Diastereodivergent [3+2] Annulation of Aromatic Aldimines with Alkenes via $\mathrm{C}-\mathrm{H}$ Activation by Half-Sandwich Rare-Earth Catalysts. J. Am. Chem. Soc. 2020. ASAP. DOI: 10.1021 /jacs.0c01171.

(16) For other examples in which Y and Sc afford enantiodivergent products, see: c) Refs 6a-c, $6 f$.

(17) Ogawa, C.; Kizu, K.; Shimizu, H.; Takeuchi, M.; Kobayashi, S. Chiral Scandium Catalysts for Enantioselective Michael Reactions of $\beta$-Ketoesters. Chem. Asian J. 2006, 1, 121-124.

(18) $\mathrm{Sc}(\mathrm{OTf})_{3}$ is typically employed as a catalyst in polar solvents: Kobayashi, S. Scandium Triflate in Organic Synthesis. European Journal of Organic Chemistry 1999, 1999, 15-27.

(19) For modern examples: see a) Lutz, F.; Igarashi, T.; Kinoshita, T.; Asahina, M.; Tsukiyama, K.; Kawasaki, T.; Soai, K. Mechanistic Insights in the Reversal of Enantioselectivity of Chiral Catalysts by Achiral Catalysts in Asymmetric Autocatalysis. J. Am. Chem. Soc. 2008, 130, 2956-2958. b) Armstrong, B. M.; Sayler, R. I.; Shupe, B. H.; Stich, T. A.; Britt, R. D.; Franz, A. K. EPR Evidence for the Origin of Nonlinear Effects in an Enantioselective $\mathrm{Cu}(\mathrm{II})$ Catalyzed Spiroannulation. ACS Catal. 2019, 9, 1224-1230. c) Nanko, M.; Shibuya, S.; Inaba, Y.; Ono, S.; Ito, S.; Mikami, K. Gem-
Digold Acetylide Complexes for Catalytic Intermolecular [4 + 2] Cycloaddition: Having Two Gold Centers Is Better for Asymmetric Catalysis. Org. Lett. 2018, 20, 7353-7357. For a thorough review of early examples of non-linear effects, see d) Ref. 20 a.

(20) For a detailed review on nonlinear effects, see a) Girard, C.; Kagan, H. B. Nonlinear Effects in Asymmetric Synthesis and Stereoselective Reactions: Ten Years of Investigation. Angew. Chem. Int. Ed. 1998, 37, 2922-2959. For a study showing a nonlinear effect in a Sc(OTf) $)_{3} \mathbf{- 1}$ catalyzed reaction: see b) Mai, E.; Schneider, C. Scandium-Bipyridine-Catalyzed Enantioselective Aminolysis of Meso-Epoxides. Chemistry - A European Journal 2007, 13, 2729-2741.

(21) Kobayashi, S.; Ogino, T.; Shimizu, H.; Ishikawa, S.; Hamada, T.; Manabe, K. Bismuth Triflate-Chiral Bipyridine Complexes as Water-Compatible Chiral Lewis Acids. Org. Lett. 2005, 7, 47294731.

(22) For a review detailing modern kinetic analysis, see: a) Blackmond, D. G. Kinetic Profiling of Catalytic Organic Reactions as a Mechanistic Tool. J. Am. Chem. Soc. 2015, 137, 10852-10866. For a kinetic study of a related Sc-bipyridine catalyzed reaction, see: b) Mukherjee, C.; Kitanosono, T.; Kobayashi, S. Kinetics Studies of the Enantioselective Hydroxymethylation of Silicon Enolates Using Aqueous Formaldehyde in the Presence of Sc(OTf)3 and a Chiral 2,2'-Bipyridine Ligand. Chem. Asian J. 2011, 6, 2308-2311.

(23) Cockerill, A. F.; Davies, G. L. O.; Harden, R. C.; Rackham, D. M. Lanthanide Shift Reagents for Nuclear Magnetic Resonance Spectroscopy. Chem. Rev. 1973, 73, 553-588.

(24) a) Cheng, G.-J.; Zhang, X.; Chung, L. W.; Xu, L.; Wu, Y.-D. Computational Organic Chemistry: Bridging Theory and Experiment in Establishing the Mechanisms of Chemical Reactions. J. Am. Chem. Soc. 2015, 137, 1706-1725. For recent examples from our groups in the area of Lewis acid catalyzed carbonyl-ene and carbonyl-olefin metathesis reactions, see b) Becker, M. R.; Reid, J. P.; Rykaczewski, K. A.; Schindler, C. S. Models for Understanding Divergent Reactivity in Lewis Acid-Catalyzed Transformations of Carbonyls and Olefins. ACS Catal. 2020, 10, 43874397. and c) Riehl, P. S.; Nasrallah, D. J.; Schindler, C. S. Catalytic, Transannular Carbonyl-Olefin Metathesis Reactions. Chem. Sci. 2019, 10, 10267-10274.

(25) See the Supporting Information for additional details.

(26) Seeman, J. I. Effect of Conformational Change on Reactivity in Organic Chemistry. Evaluations, Applications, and Extensions of Curtin-Hammett Winstein-Holness Kinetics. Chem. Rev. 1983, 83, 83-134.

(27) For examples of Lewis acid catalyzed asymmetric reactions that proceed through kinetic control see: a) Grayson, M. N.; Goodman, J. M. Asymmetric Boronate Addition to O-Quinone Methides: Ligand Exchange, Solvent Effects, and Lewis Acid Catalysis. J. Org. Chem. 2015, 80, 2056-2061. b) Grayson, M. N.; Goodman, J. M. Lewis Acid Catalysis and Ligand Exchange in the Asymmetric Binaphthol-Catalyzed Propargylation of Ketones. J. Org. Chem. 2013, 78, 8796-8801. c) Reid, J. P.; Hu, M.; Ito, S.; Huang, B.; Hong, C. M.; Xiang, H.; Sigman, M. S.; Toste, F. D. Strategies for Remote Enantiocontrol in Chiral Gold(III) Complexes Applied to Catalytic Enantioselective $\gamma, \delta$ Diels-Alder Reactions. Chem. Sci. 2020.

(28) The reaction of $\mathbf{4}$ with $\mathbf{5}$ catalyzed by Sc(OTf)3 and ligand $\mathbf{1}$ at $80{ }^{\circ} \mathrm{C}$ afforded $32 \%$ yield of product 6 in $75 \%$ ee.

(29) Cabrera, J. M.; Tauber, J.; Zhang, W.; Xiang, M.; Krische, M. J. Selection between Diastereomeric Kinetic vs Thermodynamic Carbonyl Binding Modes Enables Enantioselective IridiumCatalyzed Anti-( $\alpha$-Aryl)Allylation of Aqueous Fluoral Hydrate and Difluoroacetaldehyde Ethyl Hemiacetal. J. Am. Chem. Soc. 2018, 140, 9392-9395. 
